\title{
SOBRE FUNDAMENTALISMOS ÉTICOS
}

\author{
[On Ethical Fundamentalisms]
}

\author{
Otacílio Gomes da Silva Neto * \\ Universidade Estadual da Paraíba, Brasil
}

Resumo: A nossa história é acompanhada por diversos tipos de fundamentalismos. A proposta desse artigo é destacar alguns fundamentalismos éticos que marcaram a humanidade e que foram questionados por pensadores $\mathrm{e}$ intelectuais. A origem do fundamentalismo se dá na forma como interpretamos as doutrinas sem levarmos em consideração o espírito histórico que as cerca, ou ainda as aceitamos sem nenhuma abertura para a crítica. O fundamentalismo tem muito haver com o fanatismo, na forma como o verbete do Dicionário Filosófico (1752) de Voltaire o entende. Ao enxergar determinada doutrina como único fundamento de verdade, o ser humano é levado a uma espécie de cegueira que o impede de observar a realidade com espírito crítico. Geralmente, associamos o fundamentalismo à religião seguindo a tradição de alguns pensadores modernos, por esta ser responsável por grandes desgraças na humanidade. Porém, outros fundamentalismos também foram disseminados à margem da religião, e que da mesma forma, causaram muitos estragos à vida humana. Foi assim que se descobriram os fundamentalismos: filosófico, científico, totalitário, econômico. Parece que por mais que tentemos identificar e denunciar esses fundamentalismos, outros mais surgem nas esteiras das relações humanas. Sempre que críticos se levantam para denunciar determinados fanatismos, outros mais
Abstract: The history involves diverse types of fundamentalism. This article highlights a variety of ethical fundamentalist thoughts that marked humanity and were challenged by thinkers and intellectuals. The fundamentalism originates in the interpretation of doctrines isolated from their historical context and without room for criticism. As understood in the entry in Voltaire's Dictionnaire philosophique (1752), fundamentalism is closely related to fanaticism. The practice of interpreting any one doctrine as containing a single fundamental truth can result in a type of blindness that impedes the ability to observe reality with a critical spirit. Certain modern thinkers generally associate fundamentalism with religion and hold it responsible for great human tragedy. However, fundamentalism unrelated to religion was also spread and likewise caused insurmountable damage to human life. Fundamentalism is defined in the following terms: philosophical, scientific, totalitarian and economic. In as much as one tries to identify and denounce fundamentalism, it seems that it continues to appear in the course of human relations. Whenever critics stand against determined fanaticisms, others will arise 
fanatismos surgirão para serem combatidos. Tudo isso poderia ser banal se a vida humana não corresse nenhuma ameaça no atual estado das coisas, e se os prognósticos fossem favoráveis para a vida da nossa espécie no planeta.

Palavras-Chave: Fundamentalismo; fanatismo; ética to be denounced. This discussion might be considered trivial if the current state of affairs did not threaten human life, and if predictions were favorable for the life of our species on this planet.

KEYWORDS: Fundamentalism; fanaticism; ethics

ntes de tratarmos da temática a ser investigada faz-se necessário conceituar
o que são fundamentalismos éticos. Para isso, pelo menos uma pergunta nos é imposta: há razões que sustentam os fundamentalismos ou ele é totalmente irracional? Partiremos de uma concepção abrangente de ética. A ética entendida como ações justificadas racionalmente. Sujeitos que dizem o que sujeitos fazem. Nesse aspecto, concordamos com Peter Singer (2002, p.16) quando ele afirma que: "a ética é uma concepção". Uma concepção que por ser justificada, torna-se ética. Assim:

Os que mentem e trapaceiam, mas não acreditam que é errado o que fazem, podem estar vivendo de acordo com padrões éticos. Podem acreditar, por alguma dentre inúmeras razões possíveis, que é correto mentir, trapacear, roubar, etc. Não estão vivendo de acordo com padrões éticos convencionais, mas podem estar vivendo de acordo com outros tipos de padrões éticos (Singer, 2002, p.17).

Mesmo que não sejam padrões éticos convencionais, os fundamentalismos não podem ser considerados antiéticos, por se enquadrarem em determinados padrões éticos. A rigor, os que defendem com argumentos racionais ações consideradas fora dos padrões éticos convencionais, também são sujeitos éticos. Ainda que sejam ações consideradas fundamentalistas. Mas, o que vem a ser o fundamentalismo?

Ele não é uma doutrina, mas uma forma de interpretar e viver a doutrina. É
assumir a letra das doutrinas e normas sem cuidar de seu espírito e de sua
inserção no processo sempre cambiante da história, postura que exige contínuas
interpretações e atualizações, exatamente para manter sua verdade originária.
Fundamentalismo representa a atitude daquele que confere caráter absoluto ao seu
ponto de vista (Boff, 2009, p.49).

Observando a história considerada como palco das ações humanas, nos deparamos com situações que hoje são interpretadas como fundamentalistas. A cristandade medieval concentra as principais críticas de pensadores e intelectuais da modernidade, como período em que se tornou mais nítido o fundamentalismo. Tão logo o fundamentalismo virou sinônimo de religião. Não que a antiguidade clássica esteja completamente ausente do debate. Nela, personalidades perderam a vida, foram desterradas, por irem de encontro a determinadas doutrinas fixas e absolutas. Mas, o fato é que grande parte das críticas se concentraram na Idade Média. O que também não é de se estranhar.

Comumente, a história dos fundamentalismos está em acordo com a interpretação que foi dada aos abusos religiosos cometidos durante o período medieval: a inquisição e seus autos-de-fé; os casos Giordano Bruno e Galileu; a interpretação das sagradas escrituras como se fossem livros científicos; os milagres que davam suporte às superstições, visões e coisas afins. Conhecemos bem o resultado das ações humanas 
guiadas pela cegueira religiosa: fanatismo, preconceito, intolerância, perseguições, desterros, guerras religiosas, massacres. Atos que escandalizaram os intelectuais do iluminismo francês.

Foi com eles que a propaganda desmistificadora da religião ganhou contornos nítidos, conforme vemos nas obras de Voltaire e Diderot. Muito embora ambos não utilizem o conceito de fundamentalismo (aparentemente estranho para a época), outros conceitos semelhantes são utilizados. Encontramos no Dicionário Filosófico (1752) os verbetes: Preconceito e, principalmente, Fanatismo. De uma forma geral, esses verbetes são acompanhados de ilustrações de cunho religioso, nada admiráveis, como forma de denunciar ações causadoras de desgraças humanas, como foi o caso do massacre na noite de São Bartolomeu (1572), em que centenas de huguenotes foram assassinados por católicos nas ruas de Paris.

Para Voltaire, o fanatismo é considerado um mal, não apenas porque alguém confunde a realidade com sonhos e visões proféticas. Não há nada mal em ser um entusiasta. $\mathrm{O}$ problema reside quando o entusiasmo impulsiona a violência e com ela os crimes. Isso é o fanatismo: "Mas desde que o fanatismo atacou o cérebro de alguém, como se se tratasse duma gangrena, a doença é quase incurável" (Voltaire 1978, p.182).

O inimigo está posto. São os desvios da religião e da fé que ocasionam desordens e instabilidades. Muito daquilo que é relacionado a essas manifestações é doença, enfermidade, barbárie. Precisa-se urgentemente usar as armas e os remédios certos para combater esse inimigo. Voltaire (1978, p.182) nos oferece uma saída:

Não há outro remédio, para este mal epidêmico, que o espírito filosófico, o qual, divulgando-se pouco a pouco, acaba por suavizar os costumes dos homens e conjura os acessos do mal; porque, logo que a doença faz progressos, há que fugir a sete pés e esperar que o ar fique purificado de novo.

Nada demais para uma França que vivia os últimos fôlegos da cristandade medieval. E por isso mesmo, o poder secular usava sempre o braço de ferro para com aqueles que iam de encontro aos dogmas cristãos. Por tudo isso, o fundamentalismo acabou por ser visceralmente associado ao cristianismo e a seu primo, o judaísmo. Hoje, graças à propaganda Ocidental de cunho anglo-norte-americano, incluímos também grupos muçulmanos como os Talibãs e o Hamas, como terroristas e fundamentalistas. Eles se consideram fundamentalistas?

Voltaire não deve ser efetivamente responsabilizado pelo espírito anti-religioso que tornou-se moda entre os intelectuais do século posterior. É verdade que em muitas de suas obras o clero e a Igreja Católica são tratados derrisoriamente. Mas, o seu Tratado sobre a tolerância (1762) é uma obra que foge desses estilos zombeteiros. Nela, Voltaire exalta a razão, mas reconhece o valor do cristianismo da Reforma Protestante, além de duvidar se a intolerância pode ser fundamentada nas sagradas escrituras. Chega mesmo a afirmar que a filosofia é irmã da religião, embora uma concepção de religião não muito próxima das religiões reveladas. Na verdade, trata-se mais de uma "religião dentro dos limites da humanidade" (Cassirer, 1995, p.194).

A tradição iluminista identificou o erro, mas ao "endeusar" a razão também não acabou por se tornar fanática também? Até que ponto esse legado cuja intenção acabou por tornar-se anti-religiosa, não foi passado por gerações inteiras? Não são apenas religiosos que absolutizam seu ponto de vista, também determinados filósofos podem 
cair nesses tipos de fundamentalismos quando tornam suas verdades inquestionáveis e demonizam outros pontos de vista diferentes.

Rousseau identificou esse tipo de fundamentalismo que foi se erguendo das ruínas da cristandade. Na verdade, tratava-se de um fundamentalismo mais sutil, e por 134 isso mais perigoso por fincar suas verdades empunhando a bandeira da civilização contra a barbárie. Para Rousseau (2009, p.97): "eu vira que o fanatismo que acreditavam aniquilado estava apenas disfarçado; eu o dissera antes que ele tirasse a máscara e não esperava que fosse eu a fazer com que a tirasse".

Observando o espetáculo da sociedade, Rousseau viu o que quase ninguém viu: costumes corrompidos, pedantismo, hipocrisia. Uma falsa razão que longe de querer encontrar a verdade lutava por escondê-la sorrateiramente: no cultivo das ciências e artes, na educação, nos governos despóticos que propagandeavam a segurança e o bemestar dos cidadãos ante o véu da desigualdade moral e política. Por toda parte, a civilização do século das luzes sucumbia ante o abismo entre a verdade e a mentira: “... a intolerância do mau gosto não é menos cruel do que a das falsas religiões" (Rousseau, 2009, p.66).

Ainda assim, o título de filósofo não deixou de ser honroso por se opor ao de padre. Mas, essa probidade tinha seu tempo. Foi com Rousseau que começou o seu crepúsculo. O comtismo ${ }^{1}$ tratou de apressá-lo, pois, se temos a ciência e a técnica, para que serve a filosofia? Como a religião, a filosofia teve o seu tempo. Agora é o tempo da ciência. Desse modo, um novo fundamentalismo, o científico, se ergueu fundamentado no discurso da objetividade, neutralidade, experiência.

Não resta dúvida que vivemos numa era científica, num mundo em que há um amplo domínio da ciência. Boa parte desse amplo domínio tem causado importantes progressos na vida humana, no tocante a medicina, mobilidade, comunicação e informação. Negar esses avanços em benefício da espécie humana significa cairmos num ingênuo fundamentalismo anti-científico. Conforme Emmanuel Carneiro Leão (1989, p.12):

Quer atribuamos à ciência valor humano, quer lho neguemos, quer vejamos nela apenas algo indiferente para os valores, a ciência determina sempre o sentido do ser que somos e do ser que não somos. Decide da concepção de verdade em que vivemos, nos movemos e existimos.

Por outro lado, reconhecer a ciência como parte essencial, dominante em nossa vida, não significa o mesmo que dizer que a filosofia acabou, como nos lembra o próprio Carneiro Leão, e nem tampouco a religião (Küng, 2003). Mas, em dado momento da história há quem acreditasse assim.

Num dos programas de entrevista televisivos daqui do Brasil, o filósofo Michel Serres afirmou que quando jovem foi seduzido pelas grandes descobertas da física pós Einstein. Aí veio a Segunda Guerra Mundial com o holocausto, os milhões de mortos, feridos e mutilados, as bombas atômicas terrivelmente lançadas em Hiroshima e Nagasaki, e a confiança inabalável daquele jovem garoto na física nuclear desmoronou. As ciências exatas perderam um estudante, a tradição ganhou um renomado filósofo.

Foi um aviso duro, que a humanidade muito tardará a esquecer. O véu foi retirado: a crença absoluta no progresso da humanidade via ciência e técnica revelou-se, na verdade, como força destruidora. Ciência e técnica não são tão objetivas assim, a 
ponto de nós a divinizarmos como salvadoras da humanidade. Conforme a Adorno e Horkheimer (2011, p.100):

O que não se diz é que o terreno no qual a técnica conquista seu poder sobre a sociedade é o poder que os economicamente mais fortes exercem sobre a sociedade. A racionalidade técnica hoje é a racionalidade da própria dominação. Ela é o caráter compulsivo da sociedade alienada de si mesma. Os automóveis, as bombas e o cinema mantêm coeso o todo e chega o momento em que seu elemento nivelador mostra sua força na própria injustiça à qual servia.

Com o fim do comunismo russo e a consequente hegemonia do capitalismo, a dominação da sociedade pela tecnociência tornou-se ainda mais sutil e não menos agressiva. Se antes uma parcela significativa dos que fazem a tecnociência estava a serviço da Guerra-Fria, agora ela atende as exigências do grande mercado global alimentado pela sede de consumo de uma imensa parcela da população mundial.

O período atual tem como uma das bases esse casamento entre ciência e técnica, essa tecnociência, cujo uso é condicionado pelo mercado. Por conseguinte, tratase de uma técnica e de uma ciência seletivas. Como, frequentemente, a ciência passa a produzir aquilo que interessa ao mercado, e não à humanidade em geral, $o$ progresso técnico e científico não é sempre um progresso moral. Pior, talvez, do que isso: a ausência desse progresso moral e tudo o que é feito a partir dessa ausência vai pesar fortemente sobre o modelo de construção histórica dominante no último quartel do século XX (Santos, 2007, p.65).

Assim, um mundo está sendo propagandeado como "o melhor dos mundos possíveis", dado os avanços tecnológicos pretensamente acessíveis à população mundial. Para outros, é um mundo sem esperança dada a suposta pobreza de alternativas ao modelo que está em vigor. Por vezes assistimos indiferentes à morte da política, pois o poder real e decisório está cada vez mais distante de nós, sob a tutela das supostas democracias modernas.

Como vimos, os fundamentalismos não escolhem esta ou aquela direção, este ou aquele saber. Poderíamos nos perguntar se um dia seríamos capazes de nos livrar dos fundamentalismos. Se isso acontecesse, a que lugar seriam destinados os críticos do fundamentalismo? Essa discussão poderia terminar de forma até banal, se no estado atual da humanidade tudo estive acontecendo na melhor ordem possível. Não é assim que pensam determinados setores do capitalismo globalizado? O fato é que os efeitos nefastos dessa "nova ordem mundial" já são alarmantes, conforme a "Avaliação Ecossistêmica do Milênio" publicado por 1350 cientistas de 95 países em 2005:

1. Mais de 1 bilhão de pessoas não têm acesso a abastecimento de água potável adequado e quase 3 bilhões (ou seja, praticamente a metade da humanidade) não dispõem de infra-estrutura de saneamento. O consumo de água potável aumenta em $20 \%$ a cada dez anos, desde 1960 .

2. A concentração de dióxido de carbono na atmosfera cresceu $32 \%$, de 1750 (início da Revolução Industrial) até hoje.

3. Mais terras foram convertidas em lavoura e pasto após 1945, do que durante os séculos XVIII e XIX.

4. Hoje, entre $10 \%$ e $30 \%$ de todas as espécies de anfíbios, mamíferos e aves 
estão ameaçadas de extinção. Pelo menos um quarto das espécies de peixes está submetido à superexploração empresarial.

5. Cerca de $20 \%$ dos recifes e $35 \%$ dos manguezais existentes no mundo foram destruídos nas últimas décadas (Comparato, 2006, p.430).

Os dados parecem ser antiquados, mas quem nos garante que eles amenizaram? É por isso que nessa discussão o ceticismo deve ser afastado, pelo menos por hora. Se observarmos atentamente o que estamos fazendo agora, veríamos o quão ameaçado está o nosso futuro. É Hans Jonas um dos pensadores da atualidade que nos chama a atenção para determinadas ações globais baseada na manipulação devastadora da natureza que podem por em risco o futuro da vida no planeta.

Mas o nós hoje que lá se senta e que pode cair no abismo é a humanidade futura, e a sobrevivência das espécies é mais que um dever prudencial dos seus actuais membros. Na medida em que é o destino do homem, enquanto afectado pela condição em que estiver a natureza, tal preocupação ainda conserva a focagem antropocêntrica de toda a ética clássica (Jonas, 1994, p.38).

Se não é mentira que a ética é uma concepção, também não deixa de ser verdade que é forçoso que ela exista, conforme o referido autor: "É forçoso que exista porque os homens agem e a ética serve para ordenar as acções e regulamentar o poder de agir" (Jonas, 1994, p.60). Por isso, sempre será necessária uma nova ética para além dos fundamentalismos éticos.

\section{REFERÊNCIAS}

ADORNO, Theodor. HORKHEIMER, Max. Dialética do Esclarescimento. Trad. Guido Antonio de Almeida. Rio de Janeiro: Zahar, 2011.

BOFF, Leonardo. Fundamentalismo, terrorismo, religião e paz. Petrópolis: Vozes, 2009.

CASSIRER, Ernst. A filosofia do iluminismo. Trad. Álvaro Cabral. $2^{\mathrm{a}}$ ed. Campinas: Editora da Unicamp, 1995.

COMPARATO, Fábio Konder. Ética. São Paulo: Companhia das Letras, 2006.

JONAS, Hans. Ética Medicina e técnica. Trad. Fernando António Cascais. Lisboa: Veja, 1994.

LEÃO, Emmanuel Carneiro. Aprendendo a pensar. 2a ed. Petrópolis: Vozes, 1989.

KÜNG, Hans. Projeto de ética mundial: Uma moral ecumênica em vista da sobrevivência humana. Trad. Haroldo Reimer. $4^{\text {a }}$ ed. São Paulo: Paulinas, 2003.

ROUSSEAU, Jean-Jacques. Textos autobiográficos e outros escritos. Trad. Fúlvia M. L. Moretto. São Paulo: Editora Unesp, 2009.

SANTOS, Milton. Por uma outra globalização: do pensamento único à consciência universal. 14. Rio de Janeiro: Record: 2007.

SINGER, Peter. Ética prática. Trad. Jefferson Luiz Camargo. $3^{\text {a }}$ ed. São Paulo: Martins Fontes, 2002.

VOLTAIRE, François Marie Arouet. Tratado sobre a tolerância. Trad. Paulo Neves. $2^{\mathrm{a}}$ ed. São Paulo: Martins Fontes, 2000.

VOLTAIRE, François Marie Arouet. Várias Obras. $2^{\mathrm{a}}$ ed. Coleção Os Pensadores. Tradução de Marilena de Souza Chauí. São Paulo: Nova Cultural, 1983 (ps. 85-295).

\section{Notas}

1 Expressão derivada de Augusto Comte (1798-1857) em referência as variadas interpretações fundamentalistas que foram dadas a sua "Lei dos três estados". 